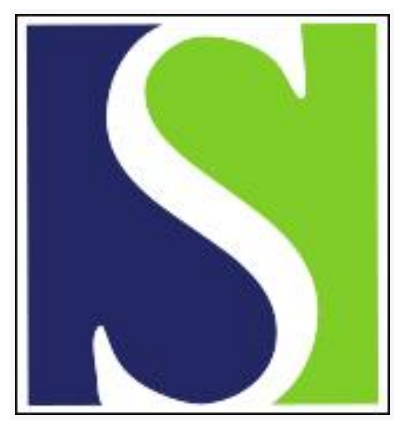

Scand J Work Environ Health 2015;41(6):519-528

https://doi.org/10.5271/sjweh.3526

Published online: 05 Oct 2015, Issue date: 01 Nov 2015

Occupational sitting time and risk of all-cause mortality among Japanese workers

by Kikuchi H, Inoue S, Odagiri Y, Inoue M, Sawada N, Tsugane S

Recent studies have revealed that prolonged sitting is a health risk, however, studies regarding occupational sitting are insufficient. Using longitudinal data from 36516 Japanese workers, we clarified that a longer duration of occupational sitting was significantly associated with higher mortality. Based on this result, sitting at work could be considered an unhealthy occupational exposure for workers.

Affiliation: Tokyo Medical University, 6-1-1 Shinjuku, Shinjuku-ku, Tokyo 160-8402, Japan. inoue@tokyo-med.ac.jp

Refers to the following texts of the Journal: 2000;26(3):227-236 2010;36(5):366-372

Key terms: all-cause mortality; Japan; Japanese worker; occupational health; occupational illness; occupational injury; occupational sitting time; risk; risk; risk; risk; risk; sedentary lifestyle

This article in PubMed: www.ncbi.nlm.nih.gov/pubmed/26575417

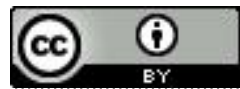




\title{
Occupational sitting time and risk of all-cause mortality among Japanese workers
}

\author{
by Hiroyuki Kikuchi, PhD, ${ }^{1}$ Shigeru Inoue, MD, PhD, ${ }^{1}$ Yuko Odagiri, MD, PhD, ${ }^{1}$ Manami Inoue, MD, \\ $P h D,{ }^{2,3}$ Norie Sawada, MD, PhD, , , 3 Shoichiro Tsugane, MD, PhD, , 3 for the Japan Public Health Centre \\ (JPHC) study group
}

\begin{abstract}
Kikuchi H, Inoue S, Odagiri Y, Inoue M, Sawada N, Tsugane S. Occupational sitting time and risk of all-cause mortality among Japanese workers. Scand J Work Environ Health. 2015;41(6):519-528. doi:10.5271/sjweh.3526

Objectives Prolonged sitting is a health risk for cardiovascular diseases and all-cause mortality, independent of moderate-to-vigorous physical activity. Epidemiological evaluation of occupational sitting has received little attention, even though it may have a potential impact on workers' health. We prospectively examined the association between occupational sitting time and all-cause mortality.
\end{abstract}

Methods Community-dwelling, Japanese workers aged 50-74 years who responded to a questionnaire in 2000-2003 were followed for all-cause mortality through 2011. Cox proportional hazard models were employed to calculate hazard ratios (HR) of all-cause mortality among middle ( $1-<3$ hours/day) or longer ( $\geq 3$ hours/day) occupationally sedentary subjects by gender or types of engaging industry ("primary industry" and "secondary or tertiary industry").

Results During 368120 person-years of follow-up (average follow-up period, 10.1 years) for the 36516 subjects, 2209 deaths were identified. Among workers in primary industry, longer duration of occupational sitting was significantly or marginally associated with higher mortality [HR $1.23,95 \%$ confidence interval $(95 \%$ CI) 1.00-1.51 among men; HR 1.34, 95\% CI 0.97-1.84 among women]. No associations were found among secondary or tertiary industry workers (men: HR $0.87,95 \%$ CI $0.75-1.01$; women: HR $1.03,95 \%$ CI $0.77-1.39$ ).

Conclusions Occupational sitting time increased all-cause mortality among primary industry workers, however similar relationships were not observed for secondary-tertiary workers. Future studies are needed to confirm detailed dose-response relationships by using objective measures. In addition, studies using cause-specific mortality data would be important to clarify the physiological underlying mechanism.

Key terms Japan; occupational health; occupational injury; occupational illness; sedentary lifestyle.

Sedentary behaviors, defined as any waking behavior characterized by an energy expenditure $<1.5$ MET (multiples of the basal metabolic rate) while in a sitting or reclining posture, such as television viewing, computer use or car-driving (1), are associated with increased all-cause mortality as well as risks of cardiovascular disease and type 2 diabetes (2-4). Studies have shown relationships between prolonged sitting and poor health outcomes independent of moderate-to-vigorous physical activity (MVPA) (5). Decreasing sedentary behavior, in addition to increasing MVPA, is now considered an important strategy to reduce health risk $(6,7)$. Owen et al suggested that sedentary time mainly consists of four domains, ie, occupational, leisure time, transportrelated, and domestic (7). In this context, many previous studies have focused on sedentary behavior in leisure time such as TV viewing time or screen time, rather than occupational sitting time (8-11).

Because occupational activities are generally determined not only by personal decision but also by job duties, chronic diseases related to "long and mandatory sitting at work" could be regarded as resulting from occupational

\footnotetext{
1 Department of Preventive Medicine and Public Health, Tokyo Medical University, Tokyo, Japan.

2 Graduate School of Medicine, The University of Tokyo, Toyko, Japan.

3 Epidemiology and Prevention Group, Research Centre for Cancer Prevention and Screening, National Cancer Centre, Tokyo, Japan.
}

Correspondence to: Shigeru Inoue, Tokyo Medical University, 6-1-1 Shinjuku, Shinjuku-ku, Tokyo 160-8402, Japan. [E-mail: inoue@ tokyo-med.ac.jp] 
exposure. Time spent in occupation generally accounts for a large part of waking hours among workers (12). Given that more workers are in occupations that require prolonged sitting times, sitting while at work needs to be assessed in terms of its possible contribution to workers' health (13).

Uffelen et al showed in their review that previous longitudinal studies seeking an association between occupational sitting and all-cause mortality have been limited and have shown inconsistent results (14). However, not all studies reviewed by Uffelen focused on occupational sitting time, with some focusing on physical inactivity (15-19), which reflects insufficient levels of MVPA. The distinction between "physical inactivity" and "sedentary behaviors" is important (1). Those who engage in high amounts of sedentary behavior can be "active" in terms of satisfying physical activity guidelines, which recommend people do 30 minutes of MVPA per day $(8,20)$. In other words, too much sitting and too little MVPA represent separate and distinct risk factors for chronic, noncommunicable diseases (eg, cardiovascular disease, diabetes or cancer) (1).

In this context, longitudinal studies aimed at evaluating influences of occupational sitting time on mortality while adjusting for MVPA are needed. However, to the best of our knowledge there is only one study, conducted in Britain, showing a positive association between occupational sitting and mortality that has evaluated both occupational sitting and MVPA (19).

The purpose of this study was to assess the association between occupational sitting time and all-cause mortality, independently from MVPA, in a Japanese cohort study.

\section{Methods}

\section{Study population}

The Japan Public Health Centre-based prospective study (JPHC study) began in 1990-1994, comprising Cohort I (started in 1990), and Cohort II (started in 1993-1994). Detailed survey procedures are explained elsewhere (21). Briefly, it targeted all registered Japanese inhabitants in 11 public health center areas who were aged 40-69 years at the beginning of the baseline survey. The participants were informed of the objectives of the study, and those who completed the survey questionnaire were regarded as consenting to participate. This survey was conducted at baseline as well as at 5-year (second) and 10 -year (third) follow-up sessions. The study protocol was approved by the institutional review board of the National Cancer Centre, Japan. Questions on occupational sitting and physical activity time were asked in the third survey only, thereby making this survey the starting point in the present study.

At baseline, 140420 individuals were identified as being in the study population. After excluding 440 persons with non-Japanese nationality $(\mathrm{N}=51)$, duplicate enrolment $(\mathrm{N}=4)$, a late report of emigration occurring before the start of the baseline study $(\mathrm{N}=378)$, or ineligibility owing to an incorrect birth date $(\mathrm{N}=7)$, a population-based cohort of 139980 individuals was established. After further excluding 13952 persons who had died or moved out of Japan, 126028 subjects remained. A total of 99447 subjects responded to the 10-year follow-up questionnaire, yielding a response rate of $79 \%$.

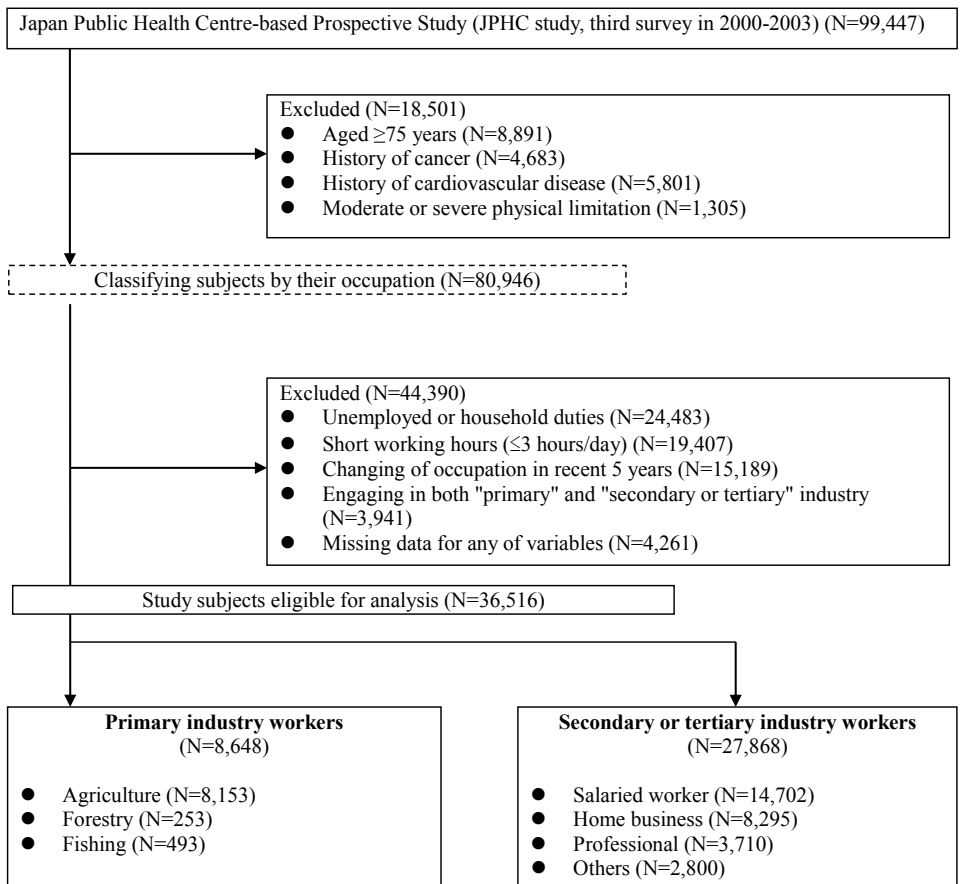

Figure 1. Flowchart of participants 


\section{Follow-up}

Participants who responded to the 10-year follow-up questionnaire were followed from the starting point until December 31, 2011. Changes in residence status, including survival, were confirmed annually by residential registry. Information on the cause of death for deceased subjects was obtained from death certificates, provided by the Japanese Ministry of Health, Labor and Welfare with permission, in which the cause of death was defined according to the International Classification of Diseases, Tenth Revision (22). Registration of death is required by the Family Registration Law and is believed to be complete.

The flow of subjects is shown in figure 1 . Because the social healthcare system is different for adults aged $\geq 75$ years in Japan, we excluded subjects aged $\geq 75$ years $(\mathrm{N}=8891)$. Subjects with a history of cancer $(\mathrm{N}=4683)$ or cardiovascular disease $(\mathrm{N}=5801)$ were also excluded.

Regarding physical limitation, participants were asked "How is your physical condition in daily life?" and given the following choices of answer: (i) no limitation; (ii) slight limitation, but they could drive vehicles or take public transportation alone; (iii) slight limitation, but they could walk around the neighborhood; (iv) partially limited, but they could go out with some assistance; (v) partially limited, and they seldom go out; (vi) moderately limited and they use a wheelchair, but they eat or evacuate by themselves; (vii) moderately limited and they need assistance to get into a wheelchair; (viii) severely limited and they lie in bed all day, but they can turn over by themselves; (ix) severely limited and they lie in bed all day, and they cannot turn over by themselves. Subjects who answered anywhere from (iii) to (ix) at the starting point were excluded $(\mathrm{N}=1305)$.

In addition, participants who were not presently employed or working in home duties only ( $\mathrm{N}=24483)$, and whose daily working hours were $\leq 3$ hours $(\mathrm{N}=19407)$ were excluded. For the purpose of investigating the impact of occupational exposure, we further excluded subjects who had changed their regular jobs within 5 years of data collection $(\mathrm{N}=15$ 189). Finally, participants who had missing information on any of the variables used in the present analysis $(\mathrm{N}=4261)$ were also excluded. Some participants had $\geq 2$ conditions for exclusion. After exclusion, 36516 participants (19 863 Japanese men and 16653 Japanese women) were eligible for analysis.

\section{Occupation categories}

The self-administered questionnaire included four multiple-choice and short-answer questions specifically related to occupation and employment status. Participants were asked "What is your current occupation?" with the following possible answer choices: (i) agriculture; (ii) forestry; (iii) fishing; (iv) salaried worker; (v) home business; (vi) professional; (vii) household duties; (viii) unemployed.

The present study defined two categories in occupation. Farmers, forestry workers, and fishermen represented "primary industry", while salaried workers, home businesses, and professionals were defined as "secondary or tertiary industry". As stated above, respondents who answered home duties and/or unemployed only ( $\mathrm{N}=24$ 483) were excluded from the present study (figure 1).

\section{Measurement of occupational sitting and physical activity time}

In our questionnaire, subjects were asked "How long do you spend in the following tasks at work?" with answer choices of "sitting tasks", "standing tasks", "walking tasks", and "strenuous tasks". Subjects were then asked the average duration of each task with the following options: (i) none; (ii) $0-<1$; (iii) $1-<3$; (iv) $3-<5$; (v) 5-<7; (vi) 7-<9; (vii) 9-<11; (viii) $>11$ hours/day. For calculating sitting and MVPA time in occupation, the midpoint of the range for each category was assigned. When minimum and maximum values were presented on the questionnaire, boundary values were assigned in the highest or lowest categories.

Average time of occupational sitting time, walking at work, and strenuous work was determined by multiplying frequency and duration. Occupational sitting time was then categorized based on the tertile value: short $(<1$ hour day), middle (1-<3 hours/day) or longer ( $\geq 3$ hours/day).

\section{Measurement of physical activity in leisure time}

Subjects were asked "How often do you engage in the following activities in your leisure time?" with the following possible answers: (i) walking slowly; (ii) brisk walking; (iii) moderate-intensity activity such as playing golf or gardening; and (iv) vigorous-intensity activity such as jogging or playing tennis. They were then asked the frequency [(a) $<1$ time/month; (b) $1-3$ times/month; (c) 1-2 times/week; (d) 3-4 times/week; (e) almost every day], and duration [(a) $<30$ minutes; (b) $30-<59$ minutes; (c) $1-<2$ hours; (d) $2-<3$ hours; (e) $3-<4$ hours; (f) $\geq 4$ hours].

The present study defined "brisk walking", "moderate intensity of activity", and "vigorous intensity or stronger intensity of activity" as MVPA in leisure time in line with the current recommendation for physical activity (23). Average time of MVPA in leisure time was determined by multiplying frequency and duration.

\section{Covariates}

Each survey gathered information on medical history and health-related behaviors. Covariates used in this 
study were age (continuous), residential area (10 public health areas), body mass index (BMI; $<18.5,18.5-<25$, or $>25 \mathrm{~kg} / \mathrm{m}^{2}$ ) (24), current smoking (yes, no), excess alcohol consumption ( $<60$ or $\geq 60 \mathrm{~g}$ ethanol/day) (25), current or history of diabetes (yes, no), current or history of hypertension (yes, no), walking time at work (continuous), strenuous work time (continuous), and MVPA in leisure time (continuous).

\section{Statistical analysis}

The number of person-years in the follow-up period was counted from the starting point (ie, date of response to the 10-year follow-up questionnaire) to the date of death, emigration from Japan, or the end of the study period, whichever came first. For subjects who withdrew from the study or were lost to follow-up, the date of withdrawal or the last confirmed date of presence in the study was used as the date of censoring.

Hazard ratios (HR) and 95\% confidence intervals $(95 \% \mathrm{CI})$ were used to characterize the relative risk of all-cause mortality associated with occupational sitting levels. To control for potential confounders, the Cox proportional hazard models were employed. The HR of all-cause mortality were calculated for middle or longer occupational sitting time, adjusting for age and residential area (Model 1). We then calculated the HR adjusted for smoking, drinking, BMI, diabetes history, and hypertension status (Model 2), then further adjusted for occupational and leisure time MVPA (Model 3). For each model, those reporting short sitting time were defined as the reference category.

Finally, occupation-stratified multivariate analyses were performed. Since very few subjects engaged in forestry and fishing, analyses were performed only for agricultural workers, salaried workers, home business, and professional workers.

In testing of the proportional hazards assumption, we scaled Schoenfeld residuals and found no violation of proportionality. Since the distribution of occupation was considerably affected by gender, all analyses were conducted separately by gender. In addition, analyses were further conducted separately by occupational classification, ie, by "primary industry" or "secondary or tertiary industry" because sitting behavior also varied by occupation. To assess the interaction between occupational and sitting time, we employed interaction terms for analyses using overall subjects. To reduce the potential for spurious associations from reverse causation, we repeated the above analyses after excluding cases with early death (those occurring within 3 years of the starting point). In the sensitivity analysis, we repeated the above analyses after excluding "subjects with slight physical limitation, but they could drive vehicles or take public transportation alone" in addition to subjects with more severe limitation; ie, analysis was performed only among subjects with no physical limitation. In addition, to ascertain possible selection bias which may occur through exclusion of subjects who have changed jobs within 5 years, we repeated this analysis including them as another sensitivity analysis.

All statistical analyses were performed using STATA software, version 12 (IBM Corp, Armonk, NY, USA); the level of significance was set at $\mathrm{P}<0.05$.

\section{Results}

During 368120 person-years of follow-up (average follow-up period, 10.1 years) for the 36516 subjects, 2209 deaths were identified.

Baseline characteristics of study subjects according to gender, occupation, and occupational sitting levels are shown in table 1 . The mean age of participants was 58.7 [standard deviation (SD) 6.2] years for men and 59.0 (SD 6.2) years for women. Subjects in secondary or tertiary industry tended to smoke and drink excess alcohol to a greater extent than those in primary industry. On comparing workers in primary industry against those in secondary or tertiary industry, we found no significant difference in characteristics except for leisure time MVPA. MVPA in leisure time was observed more among subjects with longer sitting time in both occupations.

Table 2 presents adjusted models showing associations between occupational sitting levels and all-cause mortality, stratified by gender. Overall, there is no significant association between occupational sitting duration and mortality among both men and women. Whereas, among workers in primary industry, longer duration of occupational sitting was significantly or marginally associated with higher mortality (HR 1.23, 95\% CI 1.00-1.51 among men; HR 1.34, 95\% CI 0.97-1.82 among women). Among male workers, higher occupational sitting was inversely associated in Model 1 (HR 0.83, 95\% CI 0.72-0.96). However, the association did not persist in Models 2 and 3. No apparent associations were found among female workers in secondary or tertiary industry (HR 1.03, 95\% CI 0.77-1.39). Significant interaction between occupation and sitting time were observed $(\mathrm{P}<0.001)$.

Table 3 presents the results of occupation-stratified analysis. Significant associations were observed among agricultural workers (men: HR 1.26, 95\% CI 1.01-1.56, women: HR 1.32, 95\% CI 0.95-1.82). No apparent associations were found in results for salaried workers, home business, or professional workers.

After excluding early deaths, additional analyses had no substantial effect on the results. In addition, sensitivity analyses of those with no physical limitation, as well as analyses including those who have changed jobs within five years, did not affect the results. 
Table 1. Baseline characteristics of participants. [BMI=body mass index; MVPA=moderate-to-vigorous physical activity; SD=standard deviation.]

\begin{tabular}{|c|c|c|c|c|c|c|c|c|c|c|c|c|}
\hline & & Short & h/day) & & & Middle & $1-<3 h)$ & & & Lon & $3 \mathrm{~h})$ & \\
\hline & $\mathrm{N}$ & $\%$ & Mean & SD & $\mathrm{N}$ & $\%$ & Mean & SD & $\mathrm{N}$ & $\%$ & Mean & SD \\
\hline \multicolumn{13}{|l|}{ Primary industry } \\
\hline \multicolumn{13}{|l|}{ Men } \\
\hline Number of subjects & 1561 & & & & 1220 & & & & 1219 & & & \\
\hline Age (years) & & & 63.4 & 6.6 & & & 63.8 & 6.6 & & & 63.9 & 6.3 \\
\hline BMI $\left(\mathrm{kg} / \mathrm{m}^{2}\right)$ & & & 23.5 & 2.9 & & & 23.7 & 2.9 & & & 23.7 & 2.9 \\
\hline Current smoker & & 36.6 & & & & 38.1 & & & & 37.2 & & \\
\hline Excess alcohol drinking a & & 29.0 & & & & 25.8 & & & & 25.8 & & \\
\hline \multicolumn{13}{|l|}{ History of diseases } \\
\hline Hypertension & & 22.4 & & & & 23.5 & & & & 23.9 & & \\
\hline Diabetes & & 5.5 & & & & 5.4 & & & & 6.4 & & \\
\hline MVPA in leisure time (minutes/week & & & 38.3 & 165.3 & & & 40.6 & 127.1 & & & 54.1 & 170.7 \\
\hline Walking time at work (hour/day) & & & 3.0 & 2.9 & & & 3.2 & 2.6 & & & 3.1 & 2.8 \\
\hline Strenuous work time (hour/day) & & & 3.8 & 2.8 & & & 3.6 & 2.5 & & & 3.4 & 2.8 \\
\hline \multicolumn{13}{|l|}{ Women } \\
\hline Number of subjects & 3572 & & & & 3724 & & & & 8567 & & & \\
\hline Age (years) & & & 57.8 & 5.5 & & & 57.7 & 5.5 & & & 57.2 & 5.3 \\
\hline $\mathrm{BMI}\left(\mathrm{kg} / \mathrm{m}^{2}\right)$ & & & 23.6 & 2.9 & & & 23.8 & 2.9 & & & 24.1 & 2.9 \\
\hline Current smoker & & 47 & & & & 46.1 & & & & 43.8 & & \\
\hline Excess alcohol drinking & & 31 & & & & 30.3 & & & & 30.5 & & \\
\hline \multicolumn{13}{|l|}{ History of diseases } \\
\hline Hypertension & & 17 & & & & 17.9 & & & & 19.6 & & \\
\hline Diabetes & & 7 & & & & 7.7 & & & & 7.9 & & \\
\hline MVPA in leisure time (minutes/week & & & 48.5 & 127.2 & & & 58.6 & 154.1 & & & 70.7 & 257.2 \\
\hline Walking time at work (hour/day) & & & 3.3 & 2.9 & & & 3.2 & 2.6 & & & 3.2 & 2.7 \\
\hline Strenuous work time (hour/day) & & & 3.0 & 2.8 & & & 2.8 & 2.5 & & & 2.5 & 2.6 \\
\hline \multirow{2}{*}{\multicolumn{13}{|c|}{$\begin{array}{l}\text { Secondary or tertiary industry } \\
\text { Men }\end{array}$}} \\
\hline & & & & & & & & & & & & \\
\hline Number of subjects & 3693 & & & & 3844 & & & & 8755 & & & \\
\hline Age (years) & & & 57.9 & 5.6 & & & 57.3 & 5.3 & & & 57.4 & 5.3 \\
\hline $\mathrm{BMI}\left(\mathrm{kg} / \mathrm{m}^{2}\right)$ & & & 23.7 & 2.9 & & & 23.9 & 2.9 & & & 24.1 & 2.9 \\
\hline Current smoker & & 47.4 & & & & 46.1 & & & & 44.0 & & \\
\hline Excess alcohol drinking & & 31.4 & & & & 30.1 & & & & 30.5 & & \\
\hline \multicolumn{13}{|l|}{ History of diseases } \\
\hline Hypertension & & 16.8 & & & & 17.9 & & & & 19.6 & & \\
\hline Diabetes & & 6.4 & & & & 7.5 & & & & 7.8 & & \\
\hline MVPA in leisure time (minutes/week & & & 59.0 & 168.9 & & & 78.8 & 180.0 & & & 84.1 & 186.2 \\
\hline Walking time at work (hour/day) & & & 3.0 & 2.9 & & & 2.7 & 2.5 & & & 1.7 & 2.0 \\
\hline Strenuous work time (hour/day) & & & 3.1 & 2.9 & & & 2.3 & 2.5 & & & 1.1 & 2.0 \\
\hline \multicolumn{13}{|l|}{ Women } \\
\hline Number of subjects & 2618 & & & & 3338 & & & & 6115 & & & \\
\hline Age (years) & & & 57.3 & 5.3 & & & 57.3 & 5.1 & & & 57.0 & 5.3 \\
\hline BMI $\left(\mathrm{kg} / \mathrm{m}^{2}\right)$ & & & 23.4 & 3.2 & & & 23.5 & 3.1 & & & 23.5 & 3.2 \\
\hline Current smoker & & 7.0 & & & & 7.6 & & & & 7.1 & & \\
\hline Excess alcohol drinking & & 3.1 & & & & 2.2 & & & & 3.1 & & \\
\hline \multicolumn{13}{|l|}{ History of diseases } \\
\hline Hypertension & & 17.3 & & & & 17.6 & & & & 16.8 & & \\
\hline Diabetes & & 2.9 & & & & 3.1 & & & & 2.7 & & \\
\hline MVPA in leisure time (minutes/week & & & 61.4 & 148.3 & & & 77.0 & 166.9 & & & 74.4 & 168.8 \\
\hline Walking time at work (hour/day) & & & 3.8 & 3.2 & & & 3.3 & 2.8 & & & 2.4 & 2.4 \\
\hline Strenuous work time (hour/day) & & & 1.8 & 2.5 & & & 1.4 & 2.1 & & & 0.9 & 1.7 \\
\hline
\end{tabular}

a Excess alcohol drinking was defined as $\geq 60 \mathrm{mg} /$ day intake of alcohol.

\section{Discussion}

The main finding of this study was that longer occupational sitting was significantly associated with higher mortality among workers in primary industry. Meanwhile, no apparent associations were found among workers in secondary or tertiary industry.
Previous longitudinal studies focusing on mortality and occupational physical activity showed inconsistent results $(14-19,26)$. However, most of these did not distinguish sedentary behavior from physical inactivity. The distinction between "insufficiently active" and "sedentary behaviors" is important (1). The term "physical inactivity" denotes not reaching recommendations for MVPA, whereas sedentary behaviors are defined as 
Table 2. Adjusted hazard ratios (HR) of all-cause mortality by industry, gender and sitting time. [MVPA=moderate-tovigorous physical activity; $95 \% \mathrm{Cl}=95 \%$ confidence interval]

\begin{tabular}{|c|c|c|c|c|c|c|c|c|c|}
\hline & \multirow{2}{*}{$\begin{array}{l}\text { Number of } \\
\text { Subjects }\end{array}$} & \multirow{2}{*}{$\begin{array}{l}\text { Person- } \\
\text { years }\end{array}$} & \multirow{2}{*}{$\begin{array}{l}\text { Number of } \\
\text { cases }\end{array}$} & \multicolumn{2}{|c|}{ Model $1^{\text {a }}$} & \multicolumn{2}{|c|}{ Model $2{ }^{b}$} & \multicolumn{2}{|c|}{ Model $3^{c}$} \\
\hline & & & & $\mathrm{HR}$ & $95 \% \mathrm{Cl}$ & $\mathrm{HR}$ & $95 \% \mathrm{Cl}$ & $\mathrm{HR}$ & $95 \% \mathrm{Cl}$ \\
\hline \multicolumn{10}{|l|}{ Men } \\
\hline \multicolumn{10}{|l|}{ Overall } \\
\hline Short ( $<1$ hours) & 5133 & 51499 & 545 & 1.00 & & 1.00 & & 1.00 & \\
\hline Middle (1->3 hours) & 4944 & 49284 & 510 & 0.98 & $0.86-1.11$ & 1.00 & $0.88-1.14$ & 1.00 & $0.88-1.14$ \\
\hline Long ( $\geq 3$ hours) & 9786 & 97300 & 786 & 0.92 & $0.82-1.03$ & 0.96 & $0.86-1.09$ & 0.97 & $0.86-1.09$ \\
\hline \multicolumn{10}{|l|}{ Primary industry } \\
\hline Short (<1 hours) & 1561 & 15496 & 240 & 1.00 & & 1.00 & & 1.00 & \\
\hline Middle (1->3 hours) & 1220 & 11903 & 229 & 1.13 & $0.92-1.39$ & 1.16 & $0.94-1.43$ & 1.16 & $0.94-1.43$ \\
\hline Long ( $\geq 3$ hours) & 1219 & 11825 & 220 & 1.19 & $0.97-1.46$ & 1.23 & $1.00-1.51$ & 1.23 & $1.00-1.51$ \\
\hline \multicolumn{10}{|c|}{ Secondary or tertiary industry } \\
\hline Short $(<1$ hours) & 3572 & 36003 & 305 & 1.00 & & 1.00 & & 1.00 & \\
\hline Middle (1->3 hours) & 3724 & 37381 & 281 & 0.89 & $0.75-1.05$ & 0.91 & $0.77-1.07$ & 0.91 & $0.77-1.08$ \\
\hline Long ( $\geq 3$ hours) & 8567 & 85476 & 566 & 0.83 & $0.72-0.96$ & 0.87 & $0.75-1.01$ & 0.87 & $0.75-1.01$ \\
\hline \multicolumn{10}{|l|}{ Women } \\
\hline \multicolumn{10}{|l|}{ Overall } \\
\hline Short ( $<1$ hours) & 4015 & 40925 & 143 & 1.00 & & 1.00 & & 1.00 & \\
\hline Middle (1->3 hours) & 4988 & 50725 & 197 & 1.05 & $0.83-1.33$ & 1.05 & $0.84-1.33$ & 1.06 & $0.84-1.33$ \\
\hline Long ( $\geq 3$ hours) & 7650 & 78387 & 285 & 1.15 & $0.93-1.43$ & 1.15 & $0.92-1.43$ & 1.15 & $0.92-1.42$ \\
\hline \multicolumn{10}{|l|}{ Primary industry } \\
\hline Short (<1 hours) & 1415 & 14529 & 77 & 1.00 & & 1.00 & & 1.00 & \\
\hline Middle (1->3 hours) & 1670 & 17094 & 99 & 0.98 & $0.70-1.37$ & 1.00 & $0.71-1.40$ & 1.01 & $0.73-1.42$ \\
\hline Long ( $\geq 3$ hours) & 1563 & 16128 & 118 & 1.37 & $0.99-1.88$ & 1.35 & $0.98-1.86$ & 1.34 & $0.97-1.84$ \\
\hline \multicolumn{10}{|c|}{ Secondary or tertiary industry } \\
\hline Short (<1 hours) & 2600 & 26397 & 66 & 1.00 & & 1.00 & & 1.00 & \\
\hline Middle (1->3 hours) & 3318 & 33631 & 98 & 1.11 & $0.81-1.53$ & 1.10 & $0.80-1.50$ & 1.09 & $0.80-1.51$ \\
\hline Long ( $\geq 3$ hours) & 6087 & 62259 & 167 & 1.04 & $0.78-1.39$ & 1.03 & $0.77-1.39$ & 1.03 & $0.77-1.39$ \\
\hline
\end{tabular}

a Multivariables were adjusted for age, sex and public health centres.

${ }^{\mathrm{b}}$ Model 1 + smoking, drinking, body mass index, diabetes history, walk time at work, strenuous work time, and MVPA in leisure time.

c Model $2+$ hypertension.

low-energy-expenditure activities $(\leq 1.5 \mathrm{MET})$ in a sitting or reclining posture. It has been noted that there is often little association between sedentary behavior and $\operatorname{MVPA}(27,28)$, and that it is possible for an individual to accumulate large amounts of both MVPA and sedentary behavior in the course of a day $(3,29-32)$. Hence, physically inactive workers in past studies may not actually be sedentary workers because they may spend a long time on light-intensity physical activity such as standing at work.

There has been only one cohort study that examined the relationship between occupational sitting time and all-cause mortality while distinguishing between "insufficiently active" and "prolonged sedentary" behaviors. This study evaluated occupational physical activity among 11168 British men and women (19), and found a positive association between occupational sitting and mortality among female workers independently of MVPA. Our study produced results consistent with this finding, and reinforced the evidence that longer occupational sitting time might be a health risk, at least among women in primary industry.

Regarding possible mechanisms, it has been shown that sedentary time and light-intensity activity, such as slow walking or standing tasks, are reported to be highly negatively correlated; ie, more time spent on light-inten- sity activity is associated with less time spent on sedentary behavior $(33,34)$. Furthermore, sedentary behavior includes unique biological mechanisms, as distinct from too little physical activity. Physiologically, it has been suggested that the loss of local contractile stimulation induced by prolonged sitting behavior leads to both the suppression of skeletal muscle lipoprotein lipase activity (which is necessary for triglyceride uptake and highdensity lipoprotein cholesterol production) and reduced glucose uptake through blunted translocation of GLUT-4 glucose transporters to the skeletal muscle cell surface (6). In fact, a cross-sectional study showed that frequent breaking up of sedentary time is associated with beneficial health outcomes (35). This study assessed associations between occupational sitting time and all-cause mortality. To clarify the detailed mechanisms involved, future analyses using proximal measures such as biochemical indicators or disease-specific incidence will be helpful. For example, analyses using CVD incidence would be necessary because some biological mechanisms between CVD and sedentary behaviors have been indicated $(4,33)$. Such analyses are also important for clarifying why association between occupational sitting and mortality was not found among secondary-tertiary industry workers.

The present study showed a potentially deleterious 
Table 3. Adjusted hazard ratios (HR) of all-cause mortality by occupation. Multivariables were adjusted for age, sex and public health centers, smoking, drinking, body mass index, diabetes history, hypertension status, moderate-to-vigorous physical activity (MVPA) in leisure-time and walk time at work and strenuous work time. [ $95 \% \mathrm{Cl}=95 \%$ confidence interval]

\begin{tabular}{|c|c|c|c|c|c|}
\hline & $\begin{array}{c}\text { Number of } \\
\text { subjects }\end{array}$ & $\begin{array}{c}\text { Person- } \\
\text { years }\end{array}$ & $\begin{array}{l}\text { Number } \\
\text { of cases }\end{array}$ & $\begin{array}{ll}r & H R \\
\end{array}$ & $95 \% \mathrm{Cl}$ \\
\hline \multicolumn{6}{|l|}{ Men } \\
\hline \multicolumn{6}{|l|}{ Agricultural } \\
\hline Short (<1 hours) & 1440 & 14310 & 180 & 1.00 & \\
\hline Middle (1->3 hours) & 1100 & 10814 & 157 & 1.14 & $0.92-1.42$ \\
\hline Long ( $\geq 3$ hours) & 1301 & 10134 & 161 & 1.26 & $1.01-1.56$ \\
\hline \multicolumn{6}{|l|}{ Salaried worker } \\
\hline Short (<1 hours) & 1446 & 14023 & 98 & 1.00 & \\
\hline Middle (1->3 hours) & 1625 & 15627 & 89 & 0.87 & $0.65-1.17$ \\
\hline Long ( $\geq 3$ hours) & 5353 & 51490 & 264 & 0.87 & $0.67-1.11$ \\
\hline \multicolumn{6}{|l|}{ Home business } \\
\hline Short (<1 hours) & 56 & 13 & 123 & 1.00 & \\
\hline Middle & & & 126 & 0.94 & $0.73-1.20$ \\
\hline Long ( $\geq 3$ hours) & 956 & 18782 & 183 & 0.97 & $0.76-1.22$ \\
\hline \multicolumn{6}{|l|}{ Women } \\
\hline \multicolumn{6}{|l|}{ Professional } \\
\hline Short (<1 hours) & 559 & 5652 & 43 & 1.00 & \\
\hline Middle (1->3 hours) & 527 & 5263 & 34 & 0.92 & $0.58-1.45$ \\
\hline Long ( $\geq 3$ hours) & 1094 & 10942 & 74 & 0.96 & $0.63-1.45$ \\
\hline \multicolumn{6}{|l|}{ Agriculture } \\
\hline Short ( $<1$ hours) & 97 & 14332 & 64 & 1.00 & \\
\hline Middle (1->3 r & 50 & 16 & 75 & 1.00 & $0.72-1.41$ \\
\hline Long & 1535 & 15864 & 94 & 1.32 & $0.95-1.82$ \\
\hline \multicolumn{6}{|l|}{ Salaried worker } \\
\hline Short (<1 hours) & 95 & 11725 & 21 & 1.00 & \\
\hline Middle & 1331 & 12923 & 34 & 1.46 & $0.85-2.53$ \\
\hline Long & 3 & 31010 & 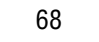 & 1.32 & $79-219$ \\
\hline \multicolumn{6}{|l|}{ Home business } \\
\hline Short (<1 hours) & & 7 & 22 & 1.00 & \\
\hline Middle (1->3 hours) & 1135 & 11261 & 34 & 1.01 & $0.58-1.74$ \\
\hline Long ( $\geq 3$ hours) & 1670 & 16832 & 53 & 1.06 & $0.63-1.77$ \\
\hline \multicolumn{6}{|l|}{ Professional } \\
\hline Short ( $<1$ hours) & 331 & 3347 & 6 & 1.00 & \\
\hline Middle (1->3 hours) & 489 & 4930 & 8 & 0.95 & $0.32-2.84$ \\
\hline Long ( $\geq 3$ hours) & 710 & 7258 & 11 & 0.80 & $0.28-2.25$ \\
\hline
\end{tabular}

impact of prolonged sitting at work. Unlike sitting in leisure time, sitting in occupational time is more likely to be mandatory. Hence, shortening the time spent sitting at work and preventing sitting-related chronic diseases might be issues relevant to occupational health. Owen et al highlighted the importance of interventions to reduce and break up sedentary behaviors among adults in domestic, workplace, and transportation environments (7). For example, the introduction of non-seated working options in occupational environments would be effective. The present study implies that such intervention might be needed.

As expected, the association between occupational sedentary time and all-cause mortality was observed among those engaging in primary industry. However, the relationship was less distinct among workers in secondary or tertiary industry. Although the specific reasons are unknown, the following are some possible explana- tions. First, we speculated that confounding by high socioeconomic status might be one reason for this unexpected result. Unfortunately, this study did not contain any appropriate indicators regarding individual socioeconomic status; however, a previous Australian study reported that sedentary workers are better educated and have a higher job class (36). It is possible that sedentary workers in secondary or tertiary industry might have higher educational achievements and income levels, which may be related to a healthy lifestyle or better health outcome. Second, the lifestyle transition after retirement may have influenced the results. Many participants in secondary or tertiary industry retired from their regular jobs during the follow-up period, and past studies showed that retirement may coincide with increased leisure time MVPA or sedentary behavior $(37,38)$. Although changes in physical activity and sedentary time after retirement are unclear, this may have been a contributory factor. A third possible reason concerns the quality of occupational sitting. Static sitting or standing tasks without adequate rest can lead to physical or mental loads among workers (39). It could be speculated that sedentary work in primary industry tends to be more deleterious in nature, whereby workers have little latitude for changing posture or are mandated to remain static or seated for long periods. By contrast, workers in secondary or tertiary industry may have relatively more freedom to sit or stand at will in their offices. Such differences in the characteristics of occupational sitting between workers in primary industry and those in secondary or tertiary industry may therefore lead to inconsistent results.

Regarding duration of occupational sitting, careful interpretation of results is needed. The present study measures sitting time by self-reported measures, which demonstrate less validity compared with objective measurement (40). In fact, accelerometer-measured sitting time among Japanese workers in secondary or tertiary industry was 327 minutes per day on average $(\mathrm{N}=102$, unpublished data). Taking this observation into consideration, self-reported occupational sitting time in this study would be underestimated. Thus, one must take care in interpreting how long is considered excessive for occupational sitting based on self-reported measures. Future epidemiological studies using objective measurements are therefore needed.

It is true that this study suggests that longer occupational sitting may be a health risk. Whereas, a study among 584 Finnish men showed that prolonged standing work in upright posture is a risk of atherosclerosis progression (41). Taking these contrasting observations into consideration, possible $\mathrm{u}$-shape associations between occupational sitting time and health risks might be speculated. In order to confirm detailed dose-response relationships, future studies using objective measures are needed. In addition, future studies are also needed 
to ascertain what aspect of occupational sitting (for example lower energy expenditure, mandatory sitting posture, or break) cause health risks.

Some limitations and strengths of our study should be considered. First, all data were collected using selfreporting measures. In particular, measurements to assess occupational physical activity and sitting time potentially suffer from misclassification. There may be workers who engage in strenuous tasks from a sitting posture. Second, we did not measure sitting time during leisure time. The observed associations may be confounded if leisure sitting time was inversely correlated with occupational sitting time. Third, changes in sedentary behavior over time may also have caused misclassification. As mentioned earlier, changes in sedentary behavior attributable to retirement need to be evaluated. Fourth, an appropriate indicator for the assessment of individual educational background, which is a potential confounder, could not be conducted due to availability of such information for half of the population (Cohort I) only in this study.

The strengths of our study are its prospective design with a large sample size, enabling us to uncover the gender-specific effects of occupational sitting and mortality. The response rate and the rate of loss to follow-up are also acceptable. Few prospective studies have focused on occupational sedentary behavior. Thus, the results of this study have implications regarding the potential occupational hazard of sedentary behavior, and suggest a need for intervention for workers engaged in sedentary occupations.

\section{Concluding remarks}

Occupational sitting time increased all-cause mortality among primary industry workers, however similar relationships were not observed for secondary-tertiary workers. Future studies are needed to confirm detailed dose-response relationships by using objective measures. In addition, studies using cause-specific mortality data would be important to clarify physiological underlying mechanism.

\section{Acknowledgements}

This study was supported by National Cancer Centre Research and Development Fund (23-A-31[toku] and 26-A-2) (since 2011) and a Grant-in-Aid for Cancer Research from the Ministry of Health, Labor and Welfare of Japan (1989-2010). Shigeru Inoue was supported by the Grant-in-Aid for Scientific Research (B): 25282209 from the Japan Ministry of Education, Culture, Sports, Science and Technology.

Manami Inoue is the beneficiary of a financial con- tribution from the AXA Research Fund as a chair holder on the AXA Department of Health and Human Security, Graduate School of Medicine, The University of Tokyo. The AXA Research Fund had no role in the design, data collection, analysis, interpretation or manuscript drafting, or in the decision to submit the manuscript for publication.

We thank the following study group members for their considerable effort to establish and manage the JPHC study.

The members of the Japan Public Health Center-based Prospective Study (JPHC Study, principal investigator: S. Tsugane) Group are: S. Tsugane, N. Sawada, M. Iwasaki, S. Sasazuki, T. Yamaji, T. Shimazu and T. Hanaoka, National Cancer Center, Tokyo; J. Ogata, S. Baba, T. Mannami, A. Okayama, and Y. Kokubo, National Cerebral and Cardiovascular Center, Osaka; K. Miyakawa, F. Saito, A. Koizumi, Y. Sano, I. Hashimoto, T. Ikuta, Y. Tanaba, H. Sato, Y. Roppongi, T. Takashima and H. Suzuki, Iwate Prefectural Ninohe Public Health Center, Iwate; Y. Miyajima, N. Suzuki, S. Nagasawa, Y. Furusugi, N. Nagai, Y. Ito, S. Komatsu and T. Minamizono, Akita Prefectural Yokote Public Health Center, Akita; H. Sanada, Y. Hatayama, F. Kobayashi, H. Uchino, Y. Shirai, T. Kondo, R. Sasaki, Y. Watanabe, Y. Miyagawa, Y. Kobayashi, M. Machida, K. Kobayashi and M. Tsukada, Nagano Prefectural Saku Public Health Center, Nagano; Y. Kishimoto, E. Takara, T. Fukuyama, M. Kinjo, M. Irei, and H. Sakiyama, Okinawa Prefectural Chubu Public Health Center, Okinawa; K. Imoto, H. Yazawa, T. Seo, A. Seiko, F. Ito, F. Shoji and R. Saito, Katsushika Public Health Center, Tokyo; A. Murata, K. Minato, K. Motegi, T. Fujieda and S. Yamato, Ibaraki Prefectural Mito Public Health Center, Ibaraki; K. Matsui, T. Abe, M. Katagiri, M. Suzuki, K. and Matsui, Niigata Prefectural Kashiwazaki and Nagaoka Public Health Center, Niigata; M. Doi, A. Terao, Y. Ishikawa, and T. Tagami, Kochi Prefectural Chuo-higashi Public Health Center, Kochi; H. Sueta, H. Doi, M. Urata, N. Okamoto, F. Ide, H. Goto and R Fujita, Nagasaki Prefectural Kamigoto Public Health Center, Nagasaki; H. Sakiyama, N. Onga, H. Takaesu, M. Uehara, T. Nakasone and M. Yamakawa, Okinawa Prefectural Miyako Public Health Center, Okinawa; F. Horii, I. Asano, H. Yamaguchi, K. Aoki, S. Maruyama, M. Ichii, and M. Takano, Osaka Prefectural Suita Public Health Center, Osaka; Y. Tsubono, Tohoku University, Miyagi; K. Suzuki, Research Institute for Brain and Blood Vessels Akita, Akita; Y. Honda, K. Yamagishi, S. Sakurai and N. Tsuchiya, University of Tsukuba, Ibaraki; M. Kabuto, National Institute for Environmental Studies, Ibaraki; M. Yamaguchi, Y. Matsumura, S. Sasaki, and S. Watanabe, National Institute of Health and Nutrition, Tokyo; M. Akabane, Tokyo University of Agriculture, Tokyo; T. Kadowaki and M. Inoue, The University of Tokyo, Tokyo; M. Noda and T. Mizoue, National Center for Global 
Health and Medicine, Tokyo; Y. Kawaguchi, Tokyo Medical and Dental University, Tokyo; Y. Takashima and Y. Yoshida, Kyorin University, Tokyo; K. Nakamura and R. Takachi, Niigata University, Niigata; J. Ishihara, Sagami Women's University, Kanagawa; S. Matsushima and S. Natsukawa, Saku General Hospital, Nagano; H. Shimizu, Sakihae Institute, Gifu; H. Sugimura, Hamamatsu University School of Medicine, Shizuoka; S. Tominaga, Aichi Cancer Center, Aichi; N. Hamajima, Nagoya University, Aichi; H. Iso and T. Sobue, Osaka University, Osaka; M. Iida, W. Ajiki, and A. Ioka, Osaka Medical Center for Cancer and Cardiovascular Disease, Osaka; S. Sato, Chiba Prefectural Institute of Public Health, Chiba; E. Maruyama, Kobe University, Hyogo; M. Konishi, K. Okada, and I. Saito, Ehime University, Ehime; N. Yasuda, Kochi University, Kochi; S. Kono, Kyushu University, Fukuoka; S. Akiba, Kagoshima University, Kagoshima; T. Isobe, Keio University; Y. Sato, Tokyo Gakugei University.

\section{Conflict of interest}

The authors declare no conflicts of interest, including related directorships, stock holdings, or contracts.

\section{References}

1. Sedentary Behaviour Research Network. Letter to the Editor: Standardized use of the terms "sedentary" and "sedentary behaviours". Applied Physiology, Nutrition, and Metabolism. 2012;37(3):540-2.

2. Wilmot E, Edwardson C, Achana F, Davies M, Gorely T, Gray $\mathrm{L}$, et al. Sedentary time in adults and the association with diabetes, cardiovascular disease and death: systematic review and meta-analysis. Diabetologia. 2012;55:2895-905. http:// dx.doi.org/10.1007/s00125-012-2677-z.

3. Owen N, Healy GN, Matthews CE, Dunstan D. Too much sitting: the population health science of sedentary behavior. Exerc Sport Sci Rev. 2010;38(3):105-13. http://dx.doi. org/10.1097/JES.0b013e3181e373a2.

4. Ford ES, Caspersen CJ. Sedentary behaviour and cardiovascular disease: a review of prospective studies. Int J Epidemiol. 2012 Oct;41(5):1338-53. http://dx.doi.org/10.1093/ije/dys078.

5. Hamilton MT, Hamilton DG, Zderic TW. Role of low energy expenditure and sitting in obesity, metabolic syndrome, type 2 diabetes, and cardiovascular disease. Diabetes. 2007 Nov;56(11):2655-67. http://dx.doi.org/10.2337/db07-0882.

6. Hamilton MT, Healy NG, Dunstan DW, Zderic TW, Owen N Too little exercise and too much sitting: Inactivity physiology and the need for new recommendations on sedentary behavior. Current Cardiovascular Risk Reports. 2008;2(4):292-8. http:// dx.doi.org/10.1007/s12170-008-0054-8.
7. Owen N, Sugiyama T, Eakin EE, Gardiner PA, Tremblay MS, Sallis JF. Adults' sedentary behavior determinants and interventions. Am J Prev Med. 2011 Aug;41(2):189-96. http:// dx.doi.org/10.1016/j.amepre.2011.05.013.

8. Dunstan DW, Barr EL, Healy GN, Salmon J, Shaw JE, Balkau $\mathrm{B}$, et al. Television viewing time and mortality: the Australian Diabetes, Obesity and Lifestyle Study (AusDiab). Circulation. 2010 Jan 26;121(3):384-91. http://dx.doi.org/10.1161/ CIRCULATIONAHA.109.894824.

9. Grontved A, Hu FB. Television viewing and risk of type 2 diabetes, cardiovascular disease, and all-cause mortality: a meta-analysis. Jama. 2011 Jun 15;305(23):2448-55. http:// dx.doi.org/10.1001/jama.2011.812.

10. Hu FB, Li TY, Colditz GA, Willett WC, Manson JE. Television watching and other sedentary behaviors in relation to risk of obesity and type 2 diabetes mellitus in women. Jama. 2003 Apr 9;289(14):1785-91. http://dx.doi.org/10.1001/ jama.289.14.1785.

11. Wijndaele K, Brage S, Besson H, Khaw KT, Sharp SJ, Luben $\mathrm{R}$, et al. Television viewing time independently predicts all-cause and cardiovascular mortality: the EPIC Norfolk study. Int J Epidemiol. 2011 Feb;40(1):150-9. http://dx.doi. org/10.1093/ije/dyq105.

12. The Ministry of Internal Affairs and Communications. Sociological research about fundamental aspects of social life in Japan. In: Bureau S, editor.: Nippon Statistics Center; 2011.

13. Brown WJ, Miller YD, Miller R. Sitting time and work patterns as indicators of overweight and obesity in Australian adults. Int J Obes Relat Metab Disord. 2003 Nov;27(11):1340-6. http://dx.doi.org/10.1038/sj.ijo.0802426.

14. van Uffelen JG, Wong J, Chau JY, van der Ploeg HP, Riphagen I, Gilson ND, et al. Occupational sitting and health risks: a systematic review. Am J Prev Med. 2010 Oct;39(4):379-88. http://dx.doi.org/10.1016/j.amepre.2010.05.024.

15. Andersen LB, Schnohr P, Schroll M, Hein HO. All-cause mortality associated with physical activity during leisure time, work, sports, and cycling to work. Arch Intern Med. 2000 Jun 12;160(11):1621-8. http://dx.doi.org/10.1001/ archinte.160.11.1621.

16. Hu G, Eriksson J, Barengo NC, Lakka TA, Valle TT, Nissinen A, et al. Occupational, commuting, and leisure-time physical activity in relation to total and cardiovascular mortality among Finnish subjects with type 2 diabetes. Circulation. 2004 Aug 10;110(6):666-73. http://dx.doi.org/10.1161/01. CIR.0000138102.23783.94.

17. Hu G, Jousilahti P, Antikainen R, Tuomilehto J. Occupational, commuting, and leisure-time physical activity in relation to cardiovascular mortality among finnish subjects with hypertension. Am J Hypertens. 2007 Dec;20(12):1242-50. http://dx.doi.org/10.1016/j.amjhyper.2007.07.015.

18. Salonen JT, Slater JS, Tuomilehto J, Rauramaa R. Leisure time and occupational physical activity: risk of death from ischemic heart disease. Am J Epidemiol. 1988 Jan;127(1):87-94.

19. Stamatakis E, Chau JY, Pedisic Z, Bauman A, Macniven R, Coombs $\mathrm{N}$, et al. Are sitting occupations associated with 
increased all-cause, cancer, and cardiovascular disease mortality risk? A pooled analysis of seven British population cohorts. PLoS ONE. 2013;8(9):e73753. http://dx.doi. org/10.1371/journal.pone.0073753.

20. Katzmarzyk P, Church T, Craig C, Bouchard C. Sitting time and mortality from all causes, cardiovascular disease, and cancer. Med Sci Sports Exerc. 2009;41:998-1005. http:// dx.doi.org/10.1249/MSS.0b013e3181930355.

21. Tsugane S, Sawada N. The JPHC study: design and some findings on the typical Japanese diet. Jpn J Clin Oncol. 2014 Sep;44(9):777-82. http://dx.doi.org/10.1093/jjco/hyu096.

22. World Health Organization. International classification of diseases and health related problem, 10th revision. Geneva: 1990.

23. Haskell WL, Lee IM, Pate RR, Powell KE, Blair SN, Franklin BA, et al. Physical activity and public health: updated recommendation for adults from the American College of Sports Medicine and the American Heart Association. Circulation. 2007 Aug 28;116(9):1081-93. http://dx.doi. org/10.1161/CIRCULATIONAHA.107.185649.

24. Matsuzawa Y, Inoue S, Ikeda Y, Sakata T, Saitou Y, Satou Y, et al. New diagnosis and classification of obesity. J Jap Soc Study Obes. 2000;6:18-28.

25. Japan health Promotion and Fitness Foundation. Healthy Japan 21 2003. Available from: http://www.kenkounippon21.gr.jp/.

26. Holtermann A, Mortensen OS, Burr H, Sogaard K, Gyntelberg F, Suadicani P. Fitness, work, and leisure-time physical activity and ischaemic heart disease and all-cause mortality among men with pre-existing cardiovascular disease. Scand J Work Environ Health. 2010 Sep;36(5):366-72. http://dx.doi. org/10.5271/sjweh.2914.

27. Biddle SJ, Gorely T, Marshall SJ, Murdey I, Cameron N. Physical activity and sedentary behaviours in youth: issues and controversies. J R Soc Promot Health. 2004 Jan;124(1):29-33. http://dx.doi.org/10.1177/146642400312400110.

28. Ekelund U, Brage S, Froberg K, Harro M, Anderssen SA, Sardinha LB, et al. TV viewing and physical activity are independently associated with metabolic risk in children: the European Youth Heart Study. PLoS Med. 2006 Dec;3(12):e488. http://dx.doi.org/10.1371/journal.pmed.0030488.

29. Healy GN, Dunstan DW, Salmon J, Shaw JE, Zimmet PZ, Owen $\mathrm{N}$. Television time and continuous metabolic risk in physically active adults. Med Sci Sports Exerc. 2008 Apr;40(4):639-45. http://dx.doi.org/10.1249/MSS.0b013e3181607421.

30. Katzmarzyk PT, Church TS, Craig CL, Bouchard C. Sitting time and mortality from all causes, cardiovascular disease, and cancer. Med Sci Sports Exerc. 2009 May;41(5):998-1005. http://dx.doi.org/10.1249/MSS.0b013e3181930355.

31. Tremblay MS, Colley RC, Saunders TJ, Healy GN, Owen N. Physiological and health implications of a sedentary lifestyle.
Appl Physiol Nutr Metab. 2010 Dec;35(6):725-40. http:// dx.doi.org/10.1139/H10-079.

32. Wong SL, Leatherdale ST. Association between sedentary behavior, physical activity, and obesity: inactivity among active kids. Prev Chronic Dis. 2009 Jan;6(1):A26.

33. Hamilton MT, Hamilton DG, Zderic TW. Exercise physiology versus inactivity physiology: an essential concept for understanding lipoprotein lipase regulation. Exerc Sport Sci Rev. 2004 Oct;32(4):161-6. http://dx.doi. org/10.1097/00003677-200410000-00007.

34. Bey L, Hamilton MT. Suppression of skeletal muscle lipoprotein lipase activity during physical inactivity: a molecular reason to maintain daily low-intensity activity. J Physiol. 2003 Sep 1;551(Pt 2):673-82. http://dx.doi. org/10.1113/jphysiol.2003.045591.

35. Healy GN, Dunstan DW, Salmon J, Cerin E, Shaw JE, Zimmet PZ, et al. Breaks in sedentary time: beneficial associations with metabolic risk. Diabetes Care. 2008 Apr;31(4):661-6. http:// dx.doi.org/10.2337/dc07-2046.

36. Davis-Lameloise N, Philpot B, Janus ED, Versace VL, Laatikainen T, Vartiainen EA, et al. Occupational differences, cardiovascular risk factors and lifestyle habits in South Eastern rural Australia. BMC Public Health. 2013;13:1090. http:// dx.doi.org/10.1186/1471-2458-13-1090.

37. Evenson KR, Rosamond WD, Cai J, Diez-Roux AV, Brancati FL. Influence of retirement on leisure-time physical activity: the atherosclerosis risk in communities study. Am J Epidemiol. 2002 Apr 15;155(8):692-9. http://dx.doi.org/10.1093/ aje/155.8.692.

38. Touvier M, Bertrais S, Charreire H, Vergnaud AC, Hercberg S, Oppert JM. Changes in leisure-time physical activity and sedentary behaviour at retirement: a prospective study in middle-aged French subjects. Int $\mathrm{J}$ Behav Nutr Phys Act. 2010;7:14. http://dx.doi.org/10.1186/1479-5868-7-14.

39. Messing K, Stock S, Cote J, Tissot F. Is sitting worse than static standing? How a gender analysis can move us toward understanding determinants and effects of occupational standing and walking. Journal of occupational and environmental hygiene. 2015 Mar;12(3):D11-7. http:// dx.doi.org/10.1080/15459624.2014.987388.

40. Lagersted-Olsen J, Korshoj M, Skotte J, Carneiro IG, Sogaard $\mathrm{K}$, Holtermann A. Comparison of objectively measured and self-reported time spent sitting. International journal of sports medicine. 2014 Jun;35(6):534-40.

41. Krause N, Lynch JW, Kaplan GA, Cohen RD, Salonen R, Salonen JT. Standing at work and progression of carotid atherosclerosis. Scand J Work Environ Health. 2000 Jun;26(3):227-36. http://dx.doi.org/10.5271/sjweh.536.

Received for publication: 15 December 2014 